\title{
The impact of the antenna phase center models on the coordinates in the EUREF Permanent Network
}

\author{
Andrzej Araszkiewicz ${ }^{1}$ (D) Christof Völksen ${ }^{2}$
}

Received: 22 March 2016/Accepted: 24 August 2016/Published online: 1 September 2016

(C) The Author(s) 2016. This article is published with open access at Springerlink.com

\begin{abstract}
Precise positioning using the signals of the Global Position System requires correcting the distance between the points of reception of the signal carrier phase and the antenna reference point. Sophisticated models to account for these phase errors are available and widely in use. These models are usually based on calibrations of several antennas of the same type to derive a mean model. There is also the possibility of applying individual correction models that are derived for one single antenna, since the individual antennas may still vary by a few millimeters. We prepared two sets of station position time series to understand the impact of using type mean or individual antenna correction models. At first, we estimated the station positions using the type mean model for the antenna corrections as it is provided by the IGS. Second, the same processing strategy was used, but this time with individual antenna correction models provided they were available. Then, based on these two solutions, we evaluated how different antenna corrections impact the network alignment and subsequently station coordinates. We showed that mixing two sources of antenna phase center corrections may influence the reference frame realization. However, this impact is very small and can be reduced by an appropriate selection of reference stations. Finally, we demonstrated that for some antennas, the
\end{abstract}

Andrzej Araszkiewicz

andrzej.araszkiewicz@wat.edu.pl

1 Faculty of Civil Engineering and Geodesy, Military University of Technology, Gen. S. Kaliskiego 2, 00-908 Warsaw, Poland

2 Commission for Geodesy and Glaciology, Bavarian Academy of Sciences and Humanities, Alfons-Goppel-Str. 11, 80539 Munich, Germany application of type mean or individual antenna calibration models may cause a discrepancy in the position of over $10 \mathrm{~mm}$ for the horizontal and vertical component. However, for most of the antennas these offsets are below $2 \mathrm{~mm}$ for horizontal components and below $4 \mathrm{~mm}$ for vertical component. Thereby, for common antennas we confirmed the results obtained by others.

Keywords GPS · Network analysis - Antenna phase center - Antenna calibration models - Time series · EPN Repro2

\section{Introduction}

The EUREF Permanent Network (EPN) was established in 1996 in order to develop a European Terrestrial Reference System (ETRS89) by analyzing data from permanent GPS sites in Europe (Torres et al. 2009; Bruyninx et al. 2012). Part of the work is carried out by several analysis centers (ACs) that process different subnetworks of the EPN. These subnetworks are later combined into one network solution for the entire EPN. During the past 20 years, the analysis of the data has always adapted to the newest standards and new strategies were developed as the analysis software improved. Ensuring the consistency between different network solutions requires the adoption of these improvements or standards by all participating analysis centers. Therefore, it became mandatory that the November 5, 2006 (GPS week 1400) absolute antenna phase center corrections (PCCs) had to be applied in the entire analysis under the auspices of EUREF. These corrections consist of phase center offsets (PCOs) and elevation- and azimuthdependent phase center variations (PCVs), which according to antenna theory (Balanis 2005) depend on the spatial 
characteristics of the radiation. This allows correcting Global Navigation Satellite Systems (GNSS) observations for the current position and satellite constellation at any time and independent for each satellite. Relative GNSS PCCs are usually estimated on a short baseline, consisting of a reference antenna [like the AOAD/M_T (Mader 1999)] and the antenna to be calibrated. Contrary to relative GNSS PCCs, absolute calibrations do not depend on a reference antenna. The absolute corrections may come either from anechoic chambers, as it was demonstrated by Schupler et al. (1994) and later refined by Görres et al. (2006), or field calibrations using a robot (Menge et al. 1998; Wübbena et al. 2006). The absolute PCCs are not influenced by multipath, as it is often the case in relative calibrations. In recent years, the field calibration procedure using a robot developed by the Institut für Erdmessung (IfE, Leibniz Universität Hannover) and Geo++ company (http://www. geopp.de) became well established and became a standard. Today, those PCCs generated by Geo++ are used by the International GNSS Service (IGS) to provide the so-called type mean calibrations, which are mean values of several individual calibrations of the same antenna type. Detailed discussions on the differences between relative and absolute calibrations have been carried out by several scientists (Mader 2000; Rothacher 2001); the advantage of the absolute PCCs is generally acknowledged.

Depending on the method of calibration, the PCCs of a GNSS antenna may differ up to several millimeters. Bilich and Mader (2010) compare the results of three methods of absolute calibration for GNSS signals. Two of them, provided by Geo++ and National Geodetic Survey (NGS), are in-field calibrations based on a robot tilting and turning the antenna in different directions while receiving all-inview GNSS signals. The third one is a recent development of the University of Bonn that requires an anechoic chamber. In this chamber, the GNSS signals are generated by a network analyzer and received by the antenna to be calibrated, which is fixed to a moveable antenna mount. They have shown that differences in PCC for various antennas can reach up to $5 \mathrm{~mm}$ at low elevations (from $0^{\circ}$ to $20^{\circ}$ ) but are usually below $2 \mathrm{~mm}$ (above $30^{\circ}$ ) for both GPS frequencies. Other studies in the field of individual calibrations have been carried out by the GNSS Research Group of the Royal Observatory of Belgium (ROB) (Baire et al. 2014) and the Geophysics Laboratory at the University of Luxembourg (LU) (Sidorov and Teferle 2016). In these experiments, the authors used the Precise Point Positioning (PPP) method to estimate the position offset related to different receiver antenna calibration models. The PPP method analyzes the GNSS data of a single station together with precise orbits and clocks. The precision is almost of the same quality as the differential analysis used by the majority of the GNSS software.
Therefore, type mean calibrations (as they are provided by the IGS in the antenna calibration file, igs08.atx) and individual calibrations were compared. ROB has selected 42 EPN stations, for which individual calibrations compiled by the EPN Central Bureau (ftp://epncb.oma.be/pub/ station/general/epnc_08.atx) are available. LU has selected 43 stations belonging to IGS, EPN, and several local networks. Finally, both groups have shown that switching between individual calibration and type mean calibrations can cause maximum position offsets up to $17 \mathrm{~mm}$ for horizontal (only one antenna/radome type) and up to $10 \mathrm{~mm}$ for the vertical component. Usually the difference is as small as a few millimeters. This is related to the difference between individual and type mean PCC patterns (here called dPCC), which affect the final position, as well as clock errors or tropospheric parameters. A comparison strategy of PCCs proposed by Schön and Kersten (2014) has exposed the complexity of this problem. They have demonstrated that horizontal components are affected mostly by azimuthal, asymmetric patterns in $\mathrm{APCC}$, and vertical patterns by elevation discrepancies. However, the total and final influence on all estimated parameters is still hard to model. Therefore, research on this issue continues to increase the accuracy and reliability of GNSS analysis.

The impact of one set of specific PCCs in GNSS analysis is particularly important if different PCC sets are available. The EPN recommends using individual PCC in every case where they are available. However, generally the GNSS data analysis should be as consistent as possible with the IGS analysis, where only type mean calibrations are used. This leads to the fact that some EPN ACs use only type mean calibrations, while others also use individual calibrations if available. The EUREF working group on EPN reprocessing was caught in the same dilemma. EPN-Repro2 is the second reprocessing campaign of the entire EPN, covering all available data of the network between 1996 and 2013. The idea behind this project is to provide a set of coordinates that are all processed under the same conditions. Therefore, the same correction models, analysis strategies, and standards are to be used. Several EPN AC's participate in this study and provide daily solutions processed with different software packages. But again, an agreement on the use of individual calibration models for the antennas has not been found. Differences between the PCCs of an individual calibration (epnc_08.atx) and the type mean PCCs (igs08.atx) are shown in Fig. 1 as an example for three EPN stations. According to Schön and Kersten (2014), rotational symmetrical components of the APCC, visible for antenna LEIAR25.R3 LEIT, should impact mostly estimated height, troposphere, and clock parameters. In the case of antenna AOAD/M_T NONE, the dPCC patterns show more asymmetries than other antennas in the EPN and it should impact mostly 

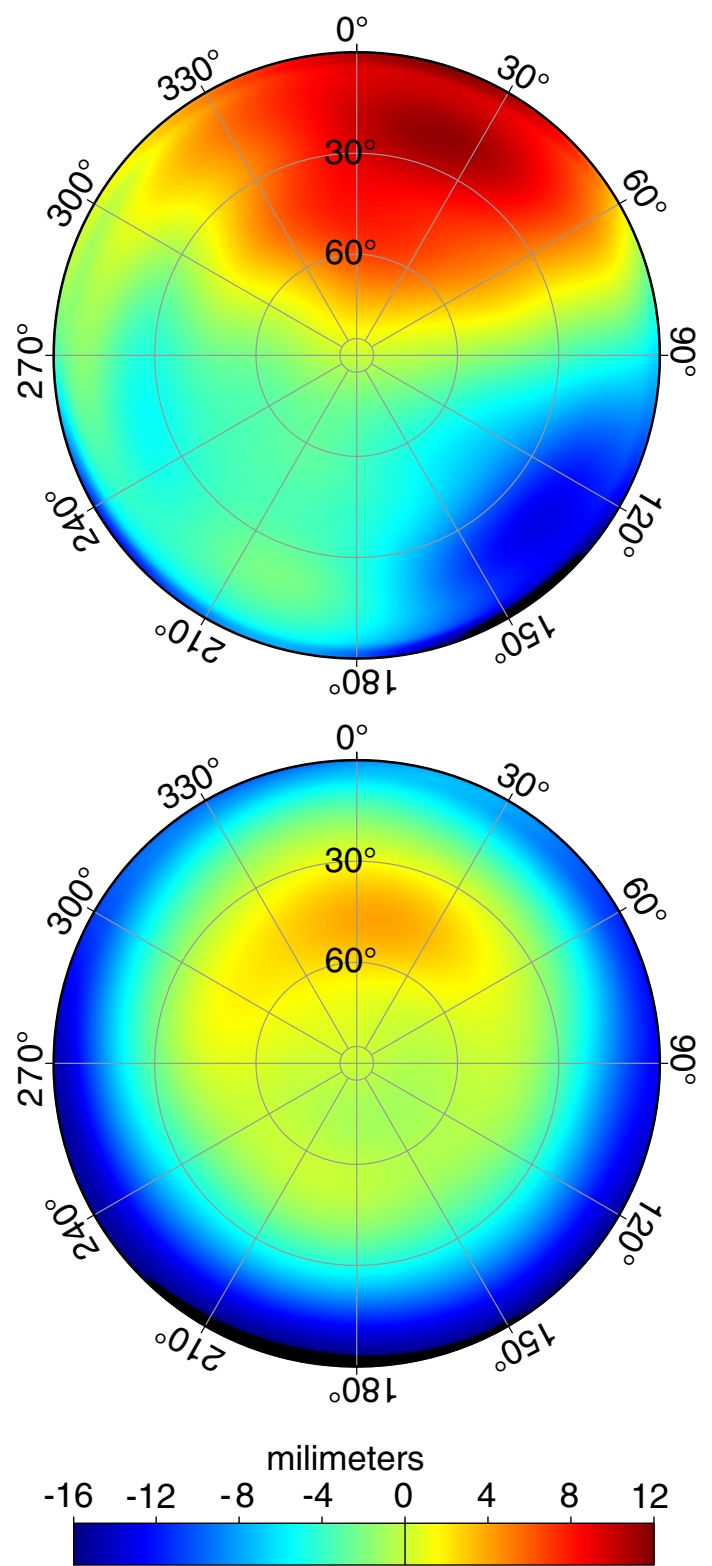

Fig. 1 Differences between individual EPN calibration and IGS type mean models on L3 for AOAD/M_T NONE mounted at METS (top) and LEIAR.R3 LEIT mounted at VAE6 (bottom)

horizontal coordinates and troposphere gradients. In the presented cases, depending on the direction of the satellite, the $\mathrm{dPCC}$ may vary from -16.8 to $+11.5 \mathrm{~mm}$, which may cause a significant difference in the estimated position. In this study, we will present the impact of using different PCCs on EPN coordinates and their time series.

\section{GPS processing}

The re-analysis performed by the Military University of Technology in Warsaw (MUT) was done using two different approaches, called here MU1 and MU2, using the

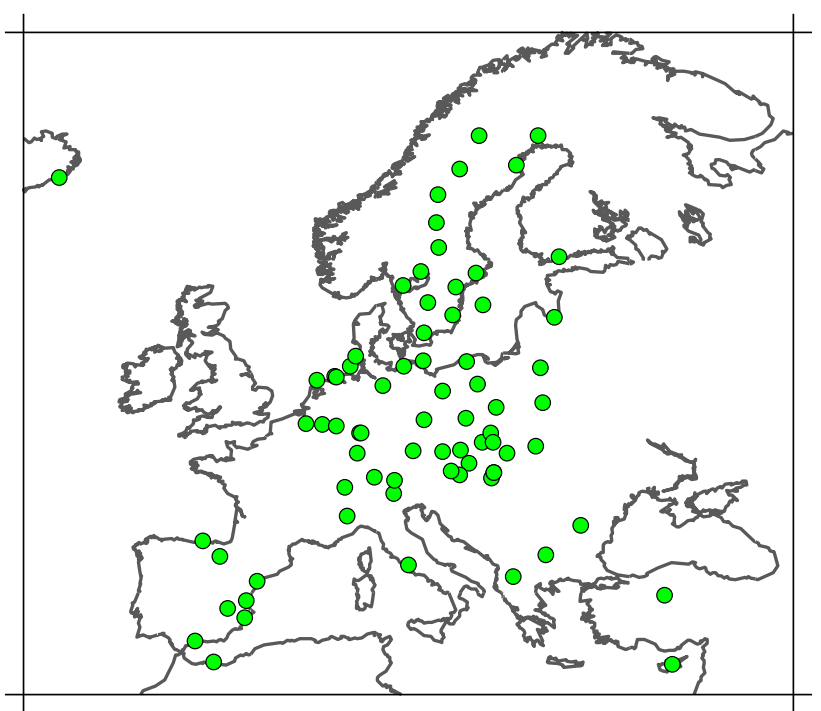

Fig. 2 EPN stations for which individual calibrations were available from epn_08.atx by the end of 2014

GPS analysis software GAMIT, version 10.50 (Herring et al. 2014). The analysis covers all stations of the EPN from January 1996 until the end of 2014. MU1 follows the EPN guidelines (http://www.epncb.oma.be/_doc umentation/guidelines/guidelines_analysis_centres.pdf) and uses individual calibrations in every case where they are available. Over the years, the number of individual calibrations has increased from one in 2002 (station HOBU in Germany) to 118 at 71 sites by the end of 2014 (Fig. 2). For rest of the stations, MU1 uses type mean calibrations based on the data set, igs08_1840.atx, provided by the IGS. MU2 uses type mean calibrations for all the stations, regardless of the individual calibrations availability.

All the other processing options were identical for MU1 and MU2. Both approaches are based on GPS only. Reprocessed orbits provided by the Centre for Orbit Determination in Europe, i.e., CODE reprocessing series 2013 (Steigenberger et al. 2014) in the reference frame IGS08 were used as fixed orbits, while for the subsequent period, the operational orbits from CODE (Dach et al. 2016) were used. The tropospheric delays were mapped to slant directions using the Vienna Mapping Function (VMF1). The zenith hydrostatic delays (ZHD) were computed from grids, which were supplied by the Technical University Vienna (Boehm et al. 2006), while the zenith wet delays (ZWD) and the local gradients were estimated during the GPS analysis in 1- and 24-h intervals, respectively. The impact of the ionosphere was removed by using the ionospheric-free combination. Second- and third-order ionospheric effects were modeled according to Petrie et al. (2010) based on the International Geomagnetic Reference Field version 11 (IGRF11) (Maus and Macmillan 2005), 
and the vertical total electron content (VTEC) obtained from global ionospheric maps (GIM), provided by CODE. The earth tides were modeled according to IERS/IGS standards. The ocean tidal loading effects were estimated based on the FES2004 model, which was provided by M.S. Bos and H.G. Scherneck, through their ocean tide calculator (http://holt.oso.chalmers.se/loading/). Nontidal atmospheric loading was applied at observation level as it is described by Tregoning and Watson (2009). This was done using the atmospheric pressure grids provided by LU (Tregoning and van Dam 2005), filtered and prepared by Massachusetts Institute of Technology (ftp://everest.mit. edu) for the analysis with GAMIT. It was used together with the IERS standard S1 and S2 tides (Ponte and Ray
2002). However, for the final solutions, the nontidal terms were removed to ensure consistency of the MUT solutions with other EPN AC solutions contributing to EPN-Repro2, also following the recommendation of the IGS (http://acc. igs.org/reprocess2.html). In order to reduce the computation time, the entire network was divided into subnetworks of 45 stations or less, while at least five stations were common in neighboring clusters. Then, the loosely constrained solutions of each subnetwork were combined into a final solution for each day. These steps were carried out independently for the approaches MU1 and MU2. Reference frame realization was done by minimizing the coordinate residuals at selected stations by estimating translation parameters (see next section for details).
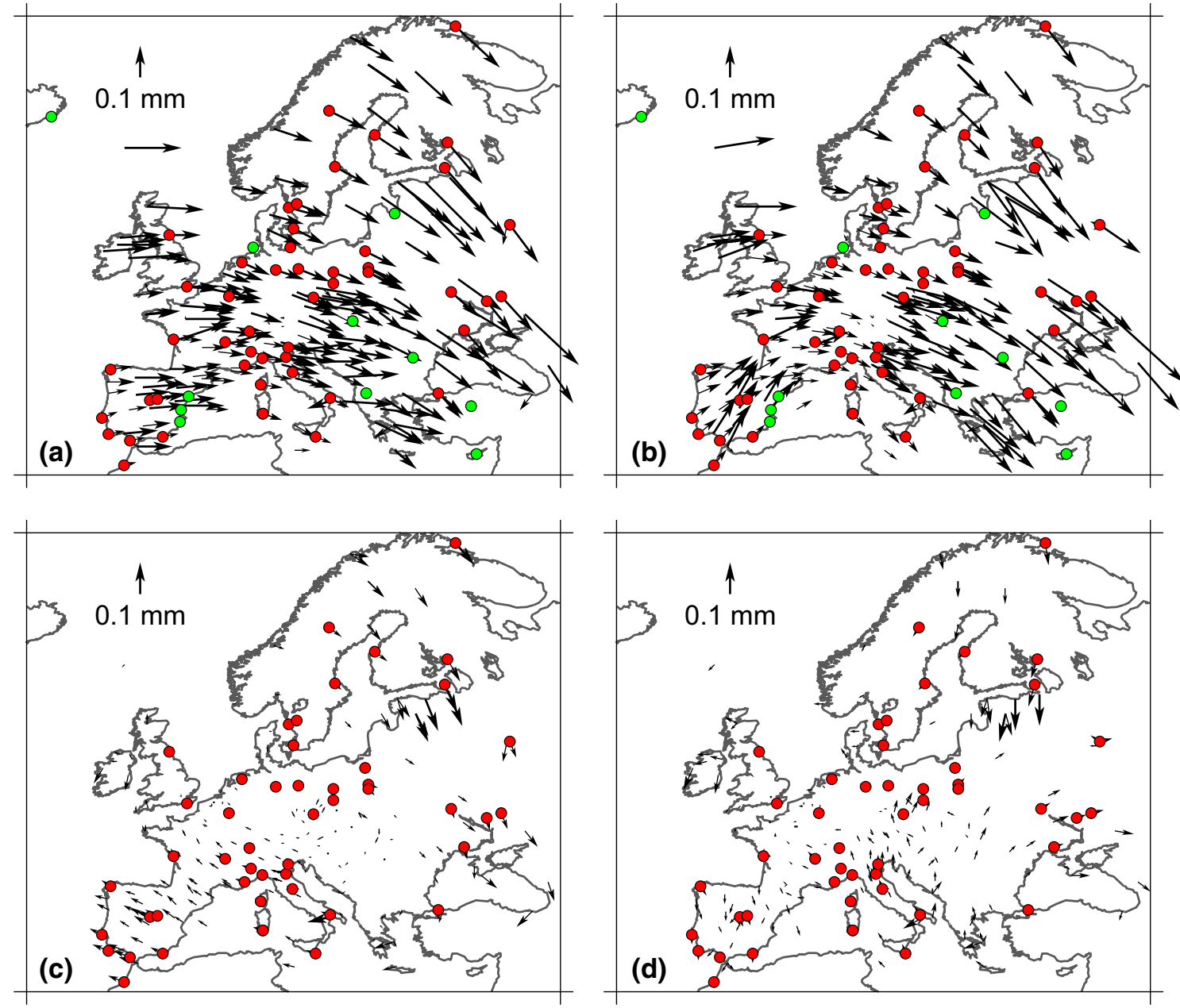

Fig. 3 Horizontal mean coordinate differences between MU1 and MU2 estimated for 234 stations identically modeled in both approaches using: 71 reference stations and estimating translation parameters (a); 71 reference stations and estimating translation plus rotation parameters (b); 57 reference stations and estimating

translation parameters (c); 57 reference stations and estimating translation plus rotation parameters (d). Reference stations modeled with individual PCCs and type mean PCCs are indicated by green and red dots, respectively 


\section{Influence of the antenna phase center correction on daily position}

Typically to determine the offsets arising from mixing different antenna models, the PPP method is used because all other error sources are identical and final coordinates are affected only by the differences of the PCCs applied. However, we used the network solution approach, because it is the most common analysis to estimate precise coordinates. Additionally, we were able to investigate if applying different antenna PCCs within the IGS and EPN analysis would impact the alignment and distort the entire EPN network significantly.

\section{Impact on the frame realization}

We prepared four variants of alignment for both solutions (MU1 and MU2) to the IGb08 frame. In the first variant (A) (Fig. 3a), we used $71 \mathrm{IGb} 08$ stations that were used for the
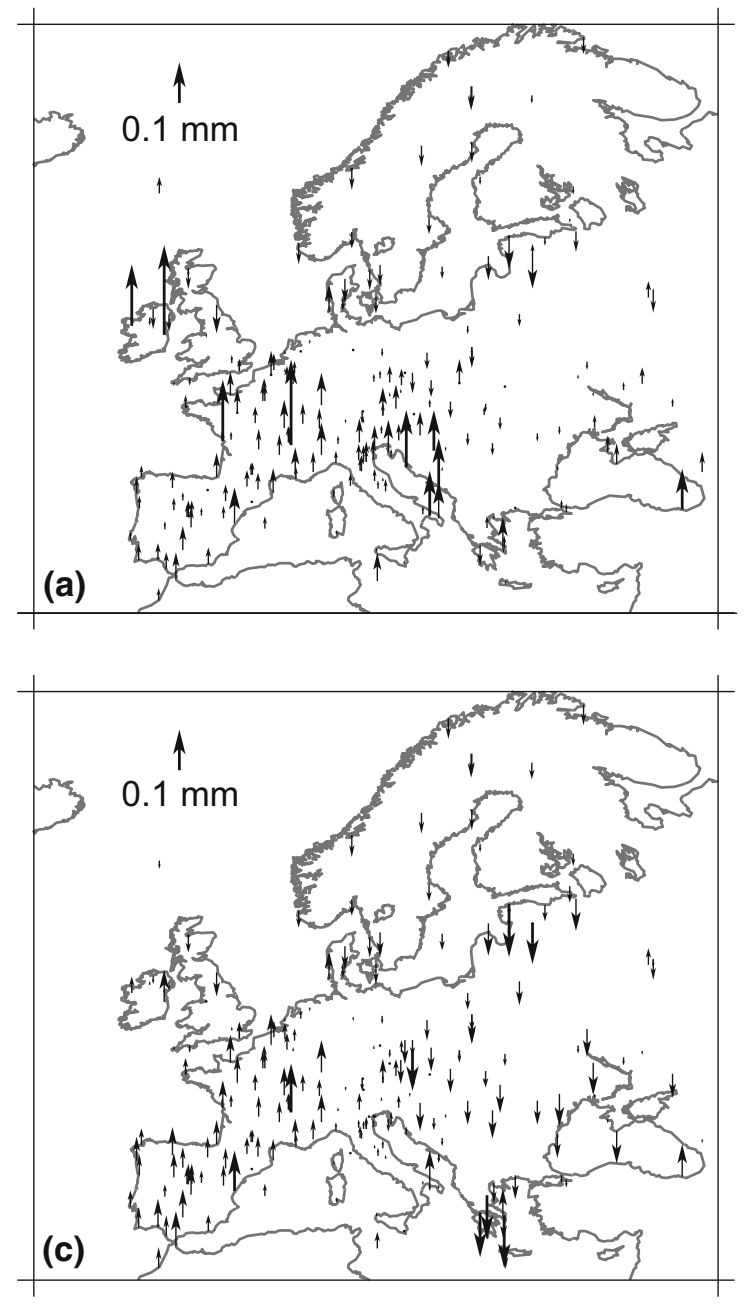

Fig. 4 Vertical mean coordinate differences between MU1 and MU2 estimated for stations identically modeled in both approaches using: 71 reference stations and estimating translation parameters (a); 71 reference generation of the weekly combined EPN solutions at beginning of 2014 (http://www.epncb.oma.be/_productsservices/ analysiscentres/combsolframe.php). Fourteen of these reference stations are equipped with antennas for which individual calibrations are available (Fig. 3a, b). Therefore, our regional solution is partially based on the individual PCCs, while IGb08 solution is fully based on the type mean PCCs. Consequently, we potentially introduced a distortion in the MU1 alignment due the fact that we mixed two solutions that are not appropriate in terms of antenna modeling options. Following to EPN weekly combination (http://www.epnacc.wat.edu.pl/ storage/comb_strateg.pdf), only transformation parameters were estimated to align the network, by minimizing the residuals at chosen reference stations (Fig. 3a). The second variant (B) (Fig. 3b) assumed the same list of reference stations as variant $\mathrm{A}$, but we also estimated rotational parameters. In the next two variants $(C$ and $\mathrm{D})$, we reduced the list of the reference stations to 57 for which only type mean PCCs are available (red dots on Fig. 3). Variant $\mathrm{C}$ estimated translation
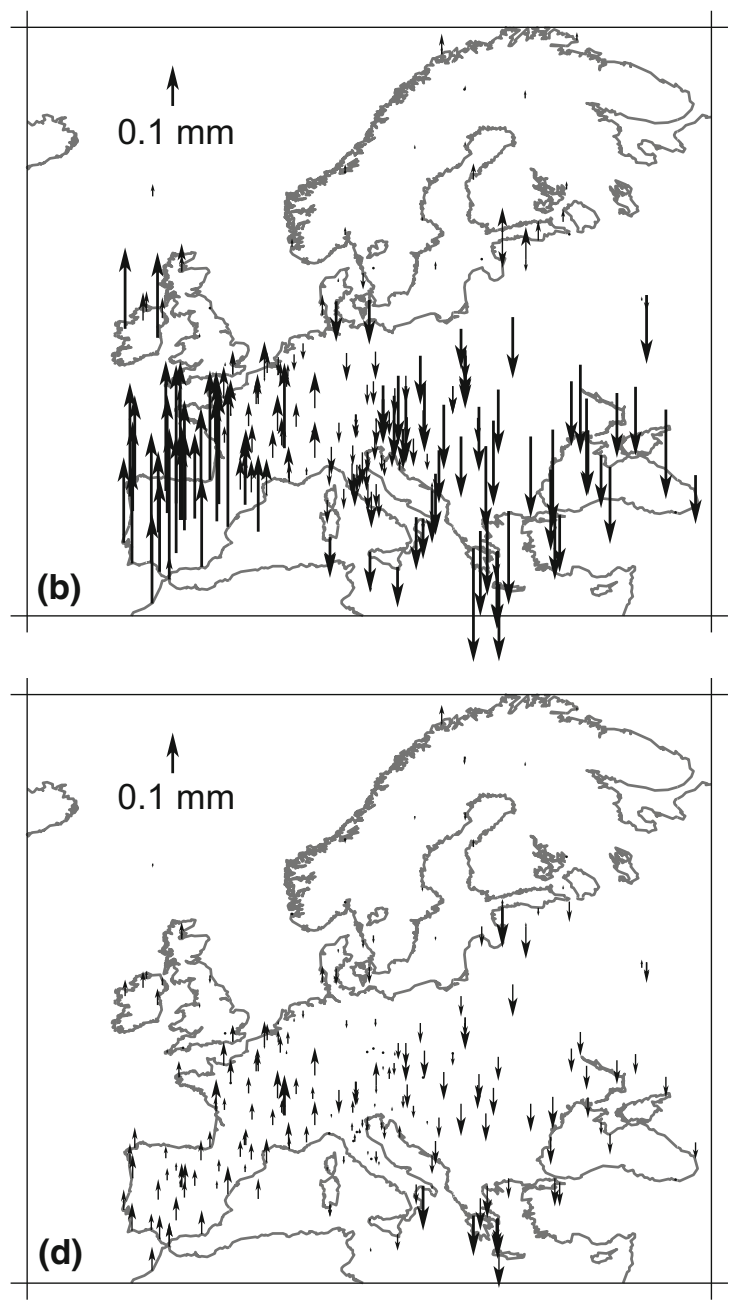

stations and estimating translation plus rotation parameters (b); 57 reference stations and estimating translation parameters $(\mathbf{c}) ; 57$ reference stations and estimating translation plus rotation parameters (d) 
parameters only, while variant $\mathrm{D}$ estimated translation plus rotation parameters (Fig. 3c, d). So the eventual distortion did not come directly from applying the different sets of reference stations, but from applying the different constraints conditions. Direct results of the analysis were two sets of daily coordinate time series of over 300 individual EPN stations for each of the 4 variants. The resulting 8 sets of coordinate time series were analyzed and cleaned from all outliers according to the classical $3 \sigma$ criterion. We do not focus on issues like position discontinuities caused by antenna changes, just the impact of using two different PCCs. For each variant, we generated time series of station coordinate differences between the MU1 and MU2 approaches. So finally, we received four sets of time series. For 234 stations that were identically modeled in approaches MU1 and MU2, we calculated the mean offset in estimated positions (Figs. 3, 4). The repeatability of the estimated differences for each station was on average $0.3 \mathrm{~mm}$ for both horizontal components and $0.6 \mathrm{~mm}$ for the vertical component.

We obtained the highest differences for variants $\mathrm{A}$ and $\mathrm{B}$, where all 71 stations were used as reference. We noticed systematic rotation (Fig. 3a, b) and tilt (Fig. 4b) of the entire network for these variants. The average horizontal offset for the second variant (Fig. 3b) is $0.11 \mathrm{~mm}$ with an RMS of $0.12 \mathrm{~mm}$. This proves that using two different antenna PCCs at reference stations can distort the entire network. However, this impact is very small and can be neglected. For variants where only 57 reference stations are used, we noticed significant improvements (Fig. 3c, d). The estimated differences can be considered as zero and prove that MU1 and MU2 solutions are in the same frame. Therefore, to proceed with the analysis we used the third variant (Figs. 3c, 4c), where only stations without individual calibrations were used as reference, and only translation parameters were estimated.

In Fig. 5 we show, as an example, the differences of two time series generated with individual PCCs (MU1) and type mean PCCs (MU2) for the station METS, which is probably responsible for the distortion of stations above the

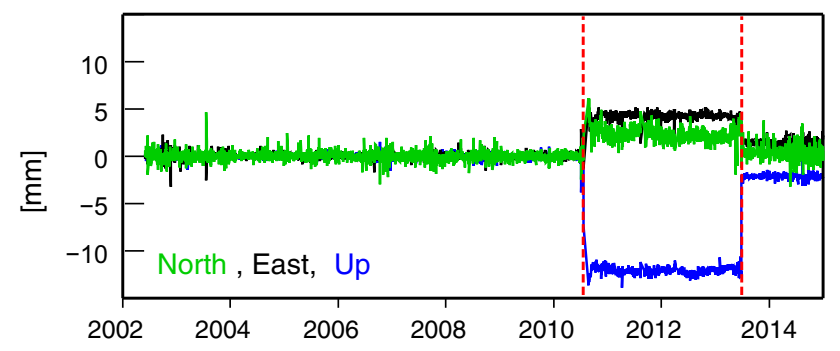

Fig. 5 Difference time series (DTS) for station METS. Discontinuities are clearly visible for the period when individual PCCs were used for the first time in solution MU2 (red lines). For the period between 2002 and 2010, the used antenna calibration models for METS are identical in both solutions MU1 and MU2 and the mean of DTS was zero
Gulf of Finland (compare Fig. 3c, d). We see significant coordinate differences from August 2010 to June 2013, which is $-11.7 \pm 0.4 \mathrm{~mm}$ for the north component, $4.1 \pm 0.3 \mathrm{~mm}$ for the east component, and finally $2.2 \pm 0.7 \mathrm{~mm}$ for the height.

\section{Impact on the annual signal in coordinate time series}

As it was noted by others, much of the seasonal signals are caused not only by geophysical loading effects but mostly by effects of the GPS technique itself or analysis errors. According to Dong et al. (2002), instrumental effects can

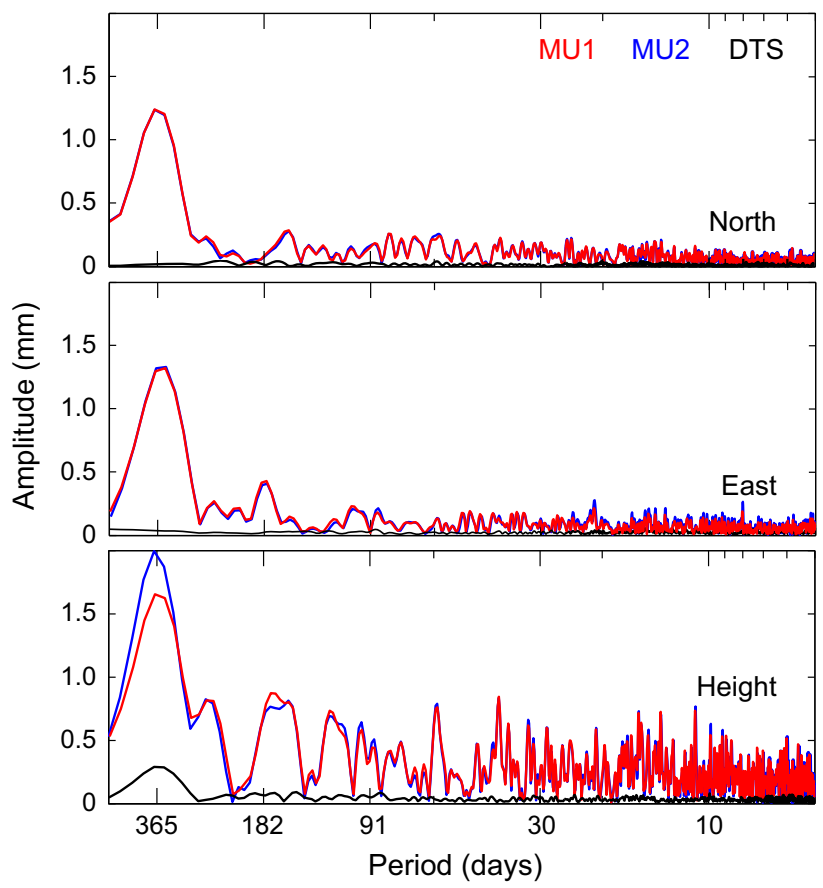

Fig. 6 Periodograms of three time series (MU1, MU2, and DTS) for LEIAR25.R3 NONE mounted at station TORI00ITA

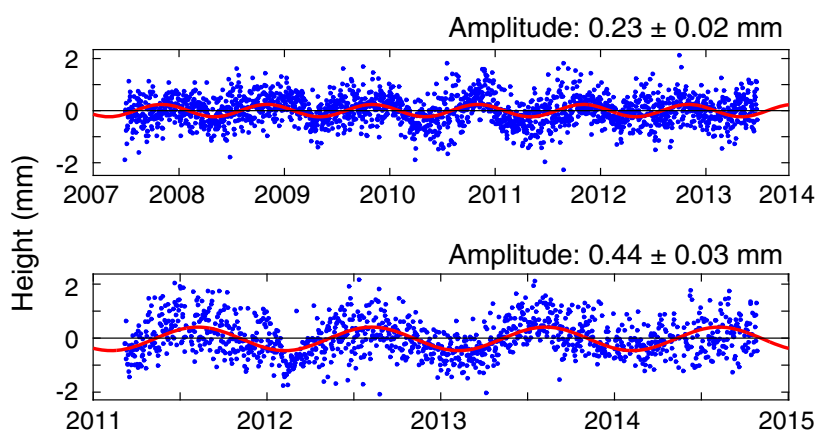

Fig. 7 Difference time series (DTS) of height for TRM55971.00 TZGD placed at KLOP (top) and LEIAR25.R3 NONE at TORI (bottom). Red curves represent fitted annual signal 

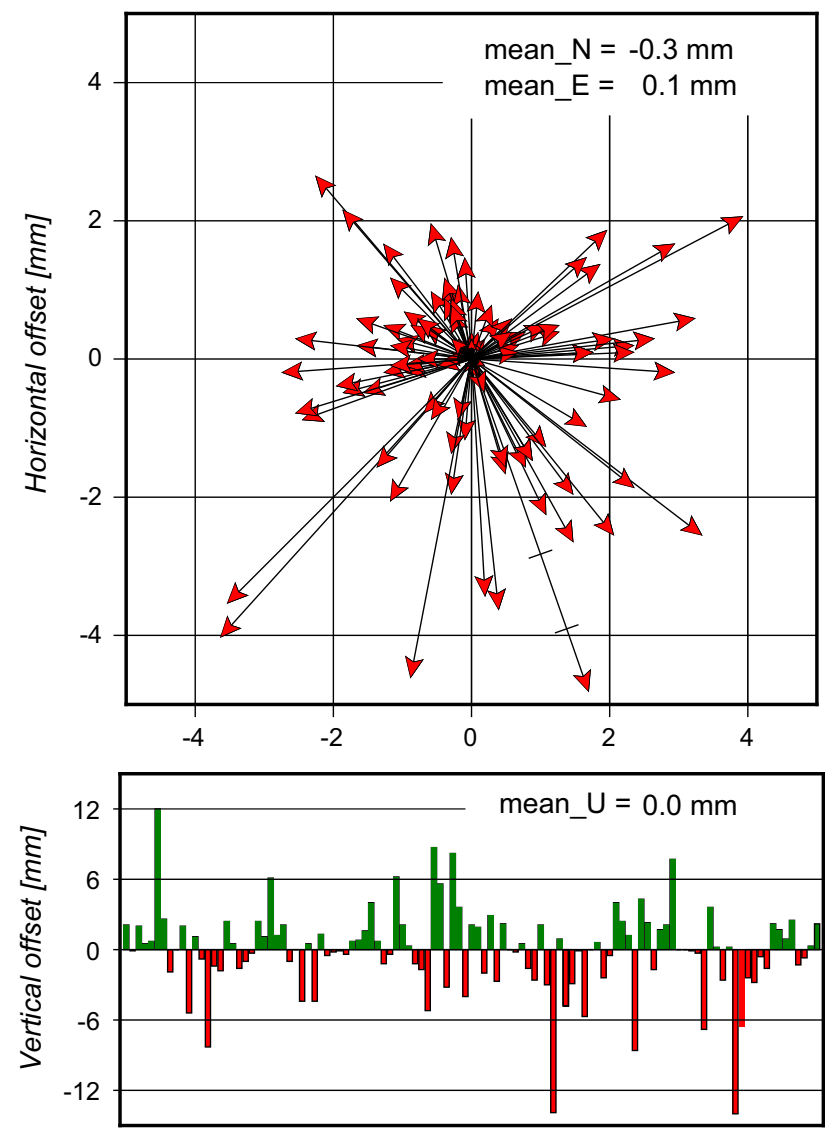

Fig. 8 Position offsets estimated for the analyzed antennas. Horizontal offsets are displayed in the top box, while the vertical offsets are displayed in the bottom (in alphabetic order by station name). Mean offsets are $-0.3 \mathrm{~mm}$ for north, $0.1 \mathrm{~mm}$ for east, and $0.0 \mathrm{~mm}$ for the Up component, with the respective RMS of $1.8,1.5$ and $3.7 \mathrm{~mm}$

be recognized as the major source of seasonal signals. It was noticed by Hatanaka et al. (2001), annual signals in the coordinate time series are the results of antenna calibration errors, as well. This motivated us to examine the impact of different antenna PCCs models on the annual signal in the coordinate time series. Since the regional solutions may absorb the common mode signal (Legrand et al. 2012), we focused only on relative changes that could be a result from applying different PCCs. We selected 56 individual calibrated antennas that were installed at one station for at least two and half years. For each of them, we prepared LombScargle periodograms of both solutions and also difference time series. This was done using the G/G MATLAB Tools (Herring 2003).

As an example, we show in Fig. 6 periodograms for LEIAR25.R3 NONE mounted at station TORI for over 3.5 years. In case of the DTS time series, the annual or semi-annual components are completely removed and no significant spectra are observable in the horizontal components. This is different for the vertical component, where we received a clear annual signal in the DTS for several antennas. Depending on the length and scatter of the DTS, the error of the estimated annual amplitude varies between 0.01 and $0.04 \mathrm{~mm}$. For 14 antennas, the amplitude exceeded $0.15 \mathrm{~mm}$ with a mean error of $0.02 \mathrm{~mm}$. As an example, the DTS of the height component for the antenna TRM55971.00 TZGD mounted at KLOP and LEIAR25.R3 NONE at TORI are shown in Fig. 7.

For only 12 antennas (Table 1), the difference of the value for the amplitude between solution MU1 and MU2 was bigger than its estimation error, which varies from 0.15 to $0.38 \mathrm{~mm}$. From the table, one can conclude that, in general, the improvement in applying individual calibration is rather small or even reversed. Following Legrand et al. (2012), the regional solutions can alter the phase of the annual signal. The resulting differences (in phase and amplitudes, as well) can therefore be the effect of network alignment. This is supported by the fact that for several unaffected stations, we noticed annual signals in the DTS. Apparently, the impact of applying different PCCs is rather small and hard to detect.

\section{Position offsets}

Despite an apparent residual annual oscillation in the DTS, the impact on the position by using different PCCs, individual or type mean, is systematic and stable over time. We used time series of different length, varying from 13 days (TRM33429.20+GP NONE at HOBU) to over 11 years (TPSCR3_GGD CONE at SASS), to estimate the mean value of the position offsets. This affected the precision of offset determination but not the offset itself. Apparently, the offsets were constant in time, as one would expect. The repeatability for individual antennas was on average $0.3 \mathrm{~mm}$ for both horizontal components and $0.6 \mathrm{~mm}$ for the vertical component. Also, similar results were obtained for the rest of the stations (Figs. 3c, 4c). Offsets were estimated for 110 antennas. The average values of offsets for all antennas were almost zero for all components (Fig. 8). The largest offset in the horizontal plane was found for AOAD/M_T NONE at station METS, and it is $12.4 \pm 0.7 \mathrm{~mm}$, as already shown in Fig. 5, whereas for the same type of antenna mounted at station WTZR, it is only $0.2 \pm 0.3 \mathrm{~mm}$. Obviously, the antenna used in METS differs significantly from the rest of this series. For over $80 \%$ of analyzed antenna, position offsets in the horizontal plane do not exceed $3.0 \mathrm{~mm}$. Only 20 antennas exceed these values (Fig. 8).

The offsets for the vertical component are significantly larger. In total, the offsets for 26 antennas are larger than $3 \mathrm{~mm}$, and for 3 of them, it exceeds even $10 \mathrm{~mm}$ (LEIAR10 NONE at station BADH and LEIAR25.R3 LEIT at stations OST6 and VAE6) and is $11.9 \pm 0.9$, $-13.9 \pm 0.7$ and $-14.0 \pm 0.8 \mathrm{~mm}$, respectively. 
Table 1 Comparison of the annual signal in height obtained for solution MU1 (1) and MU2 (2) sorted by the size of the amplitude in DTS (4)

\begin{tabular}{llllrlrl}
\hline Station & Antenna + radome & \multicolumn{2}{l}{ Amplitude of annual signal in height (mm) } & & $\begin{array}{l}\text { Phase shift between MU1 } \\
\text { and MU2 (days) }\end{array}$ \\
\cline { 3 - 6 } & & $\begin{array}{l}\text { MU1/ind. PCC } \\
(1)\end{array}$ & $\begin{array}{l}\text { MU2/type PCC } \\
(2)\end{array}$ & $\begin{array}{l}\text { (1)-(2) } \\
(3)\end{array}$ & $\begin{array}{l}\text { DTS } \\
(4)\end{array}$ \\
\hline TORI & LEIAR25.R3 NONE & $1.70 \pm 0.15$ & $2.04 \pm 0.15$ & $-0.34 \pm 0.21$ & $0.44 \pm 0.02$ & $-6 \pm 13$ \\
TUBO & LEIAR25.R4 LEIT & $1.79 \pm 0.16$ & $1.53 \pm 0.16$ & $0.26 \pm 0.23$ & $0.34 \pm 0.02$ & $-7 \pm 13$ \\
METS & AOAD/M_T NONE & $3.49 \pm 0.19$ & $3.78 \pm 0.19$ & $-0.29 \pm 0.26$ & $0.33 \pm 0.03$ & $1 \pm 16$ \\
MELI & LEIAR25.R4 LEIT & $2.97 \pm 0.22$ & $2.68 \pm 0.22$ & $0.28 \pm 0.31$ & $0.31 \pm 0.03$ & $-2 \pm 17$ \\
KLOP & TRM55971.00 TZGD & $0.26 \pm 0.12$ & $0.51 \pm 0.12$ & $-0.25 \pm 0.17$ & $0.23 \pm 0.02$ & $-14 \pm 10$ \\
BUTE & TRM55971.00 TZGD & $3.55 \pm 0.13$ & $3.32 \pm 0.13$ & $0.23 \pm 0.19$ & $0.21 \pm 0.01$ & $2 \pm 11$ \\
NICO & LEIAT504GG LEIS & $2.30 \pm 0.14$ & $2.10 \pm 0.14$ & $0.20 \pm 0.20$ & $0.21 \pm 0.02$ & $-1 \pm 12$ \\
BADH & TRM41249.00 NONE & $1.27 \pm 0.12$ & $1.07 \pm 0.12$ & $0.20 \pm 0.17$ & $0.18 \pm 0.02$ & $-2 \pm 9$ \\
HOBU & LEIAT504GG LEIS & $0.47 \pm 0.14$ & $0.68 \pm 0.14$ & $-0.21 \pm 0.20$ & $0.18 \pm 0.02$ & $11 \pm 11$ \\
ORID & LEIAT504GG LEIS & $1.38 \pm 0.05$ & $1.18 \pm 0.13$ & $0.20 \pm 0.18$ & $0.11 \pm 0.02$ & $-7 \pm 10$ \\
BORJ & LEIAR25.R3 LEIT & $1.74 \pm 0.17$ & $1.51 \pm 0.13$ & $0.23 \pm 0.18$ & $0.08 \pm 0.02$ & $-2 \pm 12$ \\
\hline
\end{tabular}

Table 2 Estimated offsets for 10 selected antennas

\begin{tabular}{llrrrl}
\hline \multirow{2}{*}{ Station } & Analyzed span time & \multicolumn{2}{l}{ Offset $(\mathrm{mm})$} & \multirow{2}{*}{ Antenna + radome } \\
\cline { 3 - 5 } & & \multicolumn{1}{l}{ North } & \multicolumn{1}{c}{ East } & \multicolumn{1}{l}{ Up } & \\
\hline VAE6 & $2014-04-13: 2014-12-31$ & $-4.7 \pm 0.3$ & $-0.9 \pm 0.4$ & $-14.0 \pm 0.8$ & LEIAR25.R3 LEIT \\
OST6 & $2014-04-13: 2014-12-31$ & $-3.7 \pm 0.4$ & $0.4 \pm 0.4$ & $-13.9 \pm 0.7$ & LEIAR25.R3 LEIT \\
METS & $2010-08-19: 2013-06-28$ & $-11.7 \pm 0.4$ & $4.1 \pm 0.3$ & $2.2 \pm 0.7$ & AOAD/M_T NONE \\
BADH & $2012-09-18: 2014-12-31$ & $0.5 \pm 0.3$ & $-1.3 \pm 0.3$ & $11.9 \pm 0.9$ & LEIAR10 NONE \\
SOFI & $2010-04-29: 2014-12-31$ & $-1.9 \pm 0.3$ & $2.4 \pm 0.3$ & $-8.6 \pm 0.7$ & LEIAR25.R3 LEIT \\
KLOP & $2007-06-27: 2013-06-28$ & $-0.1 \pm 0.3$ & $-0.5 \pm 0.3$ & $8.7 \pm 0.6$ & TRM55971.00 TZGD \\
VALE & $2010-09-16: 2014-12-31$ & $-3.6 \pm 0.3$ & $-3.6 \pm 0.3$ & $-6.7 \pm 0.9$ & LEIAR25.R3 LEIT \\
BUTE & $2007-07-31: 2013-11-04$ & $-1.2 \pm 0.3$ & $-0.1 \pm 0.2$ & $-8.3 \pm 0.6$ & TRM55971.00 TZGD \\
KUNZ & $2014-09-09: 2014-12-31$ & $0.2 \pm 0.2$ & $0.7 \pm 0.3$ & $8.2 \pm 0.5$ & TRM57971.00 NONE \\
TORI & $2011-03-08: 2014-12-31$ & $1.0 \pm 0.2$ & $0.1 \pm 0.2$ & $7.7 \pm 0.7$ & LEIAR25.R3 NONE \\
\hline Annnnnn
\end{tabular}

Antennas in descending order with respect to the maximum value of the total offset
Generally, the impact of applying two sets of PCC is distributed rather normally. The number of antennas for which offsets are negative and positive is practically the same. The mean offsets for each component are almost zero (Fig. 8). However, all antennas for which two sets of PCCs are available are diversely affected. Overall, except for some individual cases, this impact is rather small. There are also 4 antennas for which type mean values are just derived from a single individual calibration or from two calibrations. Therefore, the PCCs used in the MU1 and MU2 approach are exactly the same for these antennas (LEIAT504 OLGA, TPSCR_GGD OLGA, TPSCR3_GGD PFAN, TRM29659.00 OLGA).

As it can be seen in Table 2, all listed antennas of the type LEIAR25.R3 LEIT are similarly affected. However, we examined six types of antennas with at least three individual representatives. No significant bias was found.

There are several papers dedicated to the effect of changing PCCs models from type mean to individual and which allowed us to verify our results. Baire et al. (2014) investigate the impact of 50 antennas, 49 of those are common with our work. However, the methodology for estimating these offsets was different. For the record, they used the PPP approach based on clock and orbit parameters to estimate the precise position of a single site, while we used the classical approach based on forming double difference observations between two stations. It is likely that the relative approach based on double difference observations might not only have an impact on one single station but also the neighboring station. However, we already proved that this impact is small and can be neglected. The tropospheric modeling in the compared study was also different, which may affect the final results as it was already indicated by Baire et al. (2014). The estimated offsets do not need to be representative because they are affected by the analysis strategy. It is worth noting that applied elevation cutoff angles were also different, they used $\left(10^{\circ}\right)$ and we used $\left(5^{\circ}\right)$, which may especially affect offsets in height for antennas where dPCC exhibits the highest values at low elevation (Fig. 1, bottom). However, 
Baire et al.

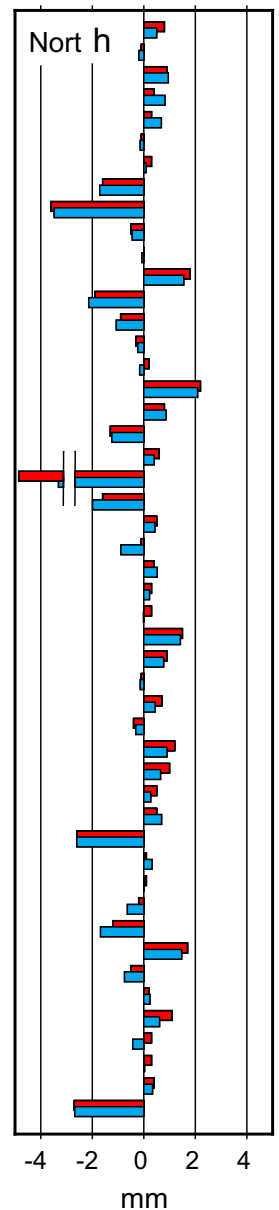

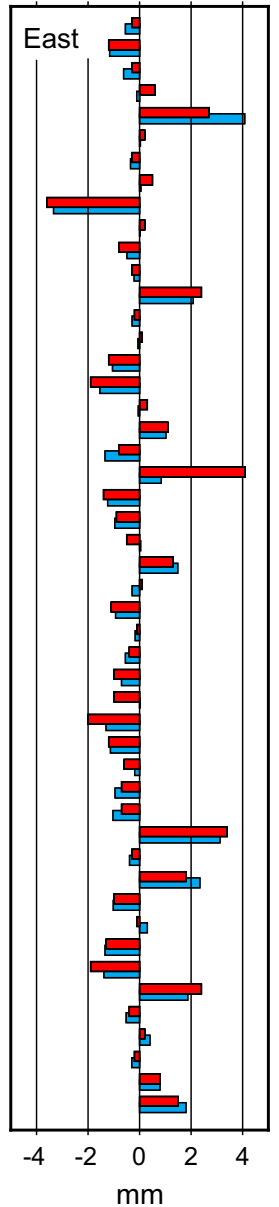

This work

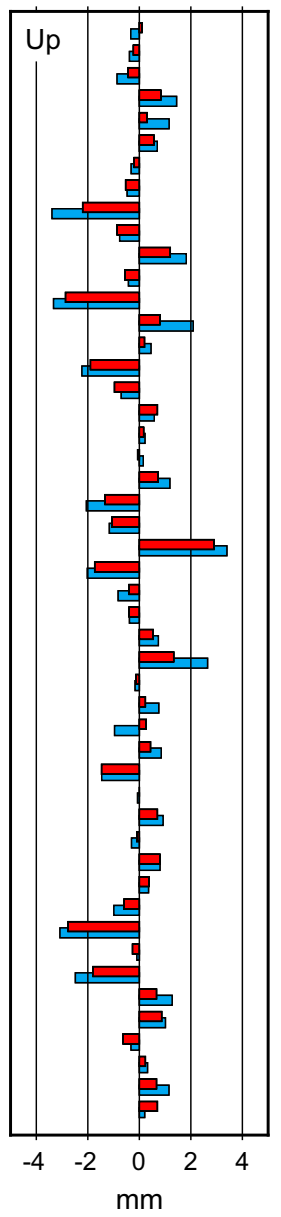

Fig. 9 Comparison of the estimated offsets for 49 common antennas with Baire et al. (2014)

besides these limitations, the results concerning the position offsets are generally consistent. The mean differences between offsets estimated by them and ourselves for the same antennas are $0.4 \mathrm{~mm}$ for the north, $0.6 \mathrm{~mm}$ for east, and $1.5 \mathrm{~mm}$ for the vertical component (Fig. 9). Only for three antennas the differences in the horizontal plane exceeded $1 \mathrm{~mm}$ [AOAD/M_T NONE at METS $(3.7 \mathrm{~mm})$, LEIAR25 LEIT at WTZR $(1.5 \mathrm{~mm})$ and LEIAT504GG LEIS at HOBU $(1.0 \mathrm{~mm})$ ]. For three antennas, the differences in height exceeded $3 \mathrm{~mm}$ [LEIAR25.R4 LEIT at HOBU $(-3.9 \mathrm{~mm})$ TPSCR3_GGD CONE at SASS $(3.8 \mathrm{~mm})$ and LEIAR25.R3 LEIT at HOE2 $(3.7 \mathrm{~mm})]$.

\section{Discussion and summary}

The aim of this study was to evaluate the impact of mixing two sets of antenna phase center models that are available for EPN stations. We have investigated the coordinate time series to determine which model is the most suitable for reducing seasonal signals. Our results clearly show that neither type mean nor individual calibration models (PCCs) do remove or reduce the seasonal signals in the time series. Our results prove that differences between type mean and individual PCCs may cause discrepancy in the final position of $10 \mathrm{~mm}$ for horizontal and vertical components. However, these are just single cases since most of the antennas difference is below $2 \mathrm{~mm}$ for the horizontal and $4 \mathrm{~mm}$ for the vertical component. The analysis based on individual antennas shows that there is practically no bias for the selected types of antenna used in the EPN. Estimated offsets can be used for verifying the various studies and services carried out under the auspices of EUREF, in which different antenna phase center models are used. We showed also that aligning regional network to IGb08 frame using different, individual or type mean, calibration models applied at reference stations influences on the results of the alignment. To be more consistent with the IGS standards and, at the same time, still follow the EPN guidelines, one can consider to use only type mean model at least at reference stations or reconsider the list of reference stations to include type mean only. However, the impact of using incompatible models at reference stations is small and negligible. Regardless of the alignment issues, it is necessary to investigate the difference between the type mean and individual calibration model whenever an individual calibration is available, and estimate its impact on the position. This is especially important to understand the possible error that a different correction model may cause. We do not completely understand the interaction of the antenna environment together with the used PCCs model, like mounting of antenna or ground at the site that has an influence on the computed position.

Acknowledgments The authors would thank to Carine Bruyninx for providing numerical values of the received offset presented in Baire et al. (2014). The authors would also thank the reviewers for their constructive comments, which improved the manuscript. This study was partly supported by statutory founds at the Institute of Geodesy, Faculty of Civil Engineering and Geodesy, Military University of Technology (No. PBS/23-933/2016). The GNSS processing was performed on the cluster computer with HP Proliant DL380 servers belonging to Centre of Applied Geomatics at the Faculty of Civil Engineering and Geodesy, Military University of Technology. Part of this work has been supported by the Federal Republic of Germany by the Akademienprogramm. The Generic Mapping Tools (Wessel and Smith 1998) and Inkscape software were used for preparing all figures. The complete list of estimated offsets is available on request.

Open Access This article is distributed under the terms of the Creative Commons Attribution 4.0 International License (http://crea tivecommons.org/licenses/by/4.0/), which permits unrestricted use, distribution, and reproduction in any medium, provided you give appropriate credit to the original author(s) and the source, provide a link to the Creative Commons license, and indicate if changes were made. 


\section{References}

Baire Q, Pottiaux E, Bruyninx C, Defraigne P, Aerts W, Legrand J, Bergeot N, Chevalier JM (2014) Influence of different GPS receiver antenna calibration models on geodetic positioning. GPS Solut 18(4):529-539. doi:10.1007/s10291-013-0349-1

Balanis CA (2005). Antenna theory: analysis design, 3rd edn. Wiley, Hoboken. ISBN: 978-0-471-66782-7

Bilich A, Mader G (2010) GNSS absolute antenna calibration at the National Geodetic Survey. In: Proceedings ION GNSS 2010, Institute of Navigation, Portland, Oregon, OR, 21-24 Sepetember, pp 1369-1377

Boehm J, Werl B, Schuh H (2006) Troposphere mapping functions for GPS and very long baseline interferometry from European centre for medium-range weather forecasts operational analysis data. J Geophys Res Solid Earth. doi:10.1029/2005JB003629

Bruyninx C, Habrich H, Söhne W, Kenyeres A, Stangl G, Völksen C (2012) Enhancement of the EUREF Permanent Network services and products. Geodesy Planet Earth IAG Symp Ser 136:27-35. doi:10.1007/978-3-642-20338-1_4

Dach R, Schaer S, Arnold D, Orliac E, Prange L, Sušnik S, Villiger S, Jäggi S (2016) CODE final product series for the IGS. Astronomical Institute, University of Bern, Bern. doi:10.7892/ boris. 75876

Dong D, Fang P, Bock Y, Cheng MK, Miyazaki S (2002) Anatomy of apparent seasonal variations from GPS-derived site position time series. J Geophys Res 107(B4):2075. doi:10.1029/ 2001JB000573

Görres B, Campbell J, Becker M, Siemes M (2006) Absolute calibration of GPS antennas: laboratory results and comparison with field and robot techniques. GPS Solut 10(2):136-145. doi:10.1007/s10291-005-0015-3

Hatanaka Y, Sawada M, Horita A, Kusaka M, Johnson J, Rocken C (2001) Calibration of antenna-radome and monument-multipath effect of GEONET-Part 2: evaluation of the phase map by GEONET data. Earth Planets Space 53:23-30

Herring TA (2003) MATLAB tools for viewing GPS velocities and time series. GPS Solut 7(3):194-199. doi:10.1007/s10291-0030068-0

Herring TA, King RW, Floyd A, McClusky SC (2014) Documentation for the GAMIT GPS analysis software 10.5. Massachusetts Institute of Technology Internal Report, USA

Legrand J, Bergeot N, Bruyninx C, Wöppelmann G, SantamariaGomez A, Bouin MN, Altamimi Z (2012) Comparison of regional and global GNSS positions, velocities and residual time series. In: Kenyon S, Pacino MC, Marti U (eds) Geodesy for planet earth, international association of geodesy symposia, vol 136. Springer, Berlin, pp 95-103. doi:10.1007/978-3-642-20338$1 \_12$

Mader GL (1999) GPS antenna calibration at the National Geodetic Survey. GPS Solut 3(1):50-58. doi:10.1007/PL00012780

Mader G (2000) A comparison of absolute and relative GPS antenna calibrations. In: Proceedings of preprint IGS analysis workshop 2000, IGS Electronic Mail, 20 November, Message no 3107

Maus S, MacMillan S (2005) 10th Generation International geomagnetic reference field. EOS Trans Am Geophys Union. doi:10. 1029/2005EO160006.issn:0096-3941

Menge F, Seeber G, Völksen C, Wübbea G, Schmitz M (1998) Results of absolute field calibration of GPS antenna PCV. In: Proceedings ION GPS 1998, Institute of Navigation, Nashville, Tennessee, TN, 15-18 September, 1998
Petrie EJ, King MA, Moore P, Lavallée DA (2010) Higher-order ionospheric effects on the GPS reference frame and velocities. J Geophys Res Soli Earth 115:B03417. doi:10.1029/ 2009JB006677

Ponte RM, Ray R (2002) Atmospheric pressure corrections in geodesy and oceanography: a strategy for handling air tides. Geophys Res Lett. doi:10.1029/GL016340

Rothacher M (2001) Comparison of absolute and relative antenna phase center variations. GPS Solut 4(4):55-60

Schön S, Kersten T (2014) Comparing antenna phase center corrections: challenges, concepts and perspectives. IGS AC Workshop 2014 Link. https://www.ife.uni-hannover.de/uploads/ tx_tkpublikationen/IGS2014_schoenKersten.pdf

Schupler BR, Allshouse RL, Clark TA (1994) Signal Characteristics of GPS USER antennas. Navigation 41(3):277-295

Sidorov D, Teferle FN (2016) Impact of antenna phase centre calibrations on position time series: preliminary results. In: IAG symposia series. Springer, Berlin, pp 1-7. doi: 10.1007/1345_ 2015_216

Steigenberger P, Lutz S, Dach R, Schaer S, Jäggi S (2014) CODE repro2 product series for the IGS. Astronomical Institute, University of Bern, Bern. doi:10.7892/boris.75680

Torres JA, Altamimi Z, Boucher C, Brockmann E, Bruyninx C, Caporali A, Gurtner W, Habrich H, Hornik H, Ihde J, Kenyeres K, Mäkinen J, v d Marel H, Seeger H, Simek G, Weber G (2009) Status of the European reference frame (EUREF), observing our changing earth. IAG Symp Ser 133:47-56. doi:10.1007/978-3540-85426-5

Tregoning P, van Dam T (2005) Atmospheric pressure loading corrections applied to GPS data at the observation level Geophys. Res Lett 32:L22310. doi:10.1029/2005GL024104

Tregoning P, Watson C (2009) Atmospheric effects and spurious signals in GPS analyses. J Geophys Res 114:B09403. doi:10. 1029/2009JB006344

Wessel P, Smith WH (1998) New, improved version of Generic Mapping Tools released. Eos Trans 79:579

Wübbena G, M Schmitz, G Boettcher, C Schumann (2006) Absolute GNSS antenna calibration with a robot: repeatability of phase variations, calibration of GLONASS and determination of carrier-to-noise pattern. In: Proceedings of the IGS workshop 2006 perspectives and visions for 2010 and beyond, May 8-12, Darmstadt, Germany

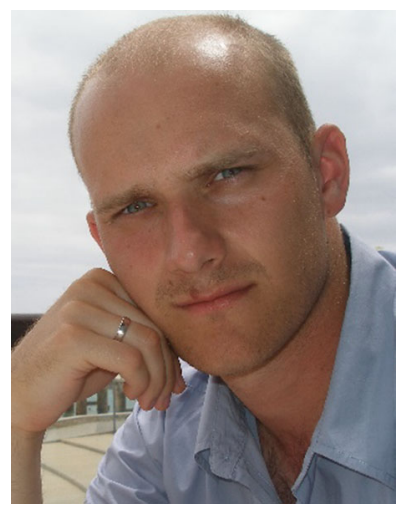

Andrzej Araszkiewicz is an assistant professor at the Faculty of Civil Engineering and Geodesy, Military University of Technology in Warsaw, Poland. He received a Ph.D., in Geodesy and Cartography in 2014. His research interests are mainly focused in general geophysical studies with GNSS techniques in long- and short-time scales. 


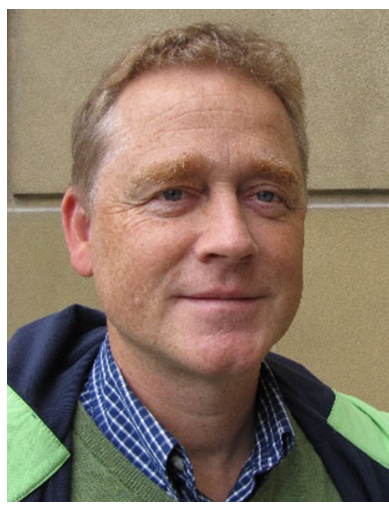

Christof Völksen is a senior research associate in the Commission for Geodesy and Glaciology at the Bavarian Academy of Sciences and Humanities in Munich, Germany. He has been involved in research on GNSS positioning since 1992. He holds a Dr.-Ing. degree in geodesy from the University of Hannover since 1999. 